\title{
Component-/Structure-dependent Elasticity of Solid Electrolyte Interphase Layer in Li-ion Batteries: Experimental and Computational Studies
}

\author{
Hosop Shin ${ }^{\mathrm{a}}$, Jonghyun Park ${ }^{\mathrm{a}^{*}}$, Sangwoo Han ${ }^{\mathrm{a}}$, Ann Marie Sastry ${ }^{\mathrm{b}}$, and Wei Lu ${ }^{\mathrm{a}}$ \\ ${ }^{a}$ Department of Mechanical Engineering, University of Michigan, Ann Arbor, MI 48109, USA \\ ${ }^{\mathrm{b}}$ Sakti3, Inc., Ann Arbor, MI 48108, USA
}

Present Address of the corresponding Author: Department of Mechanical and Aerospace Engineering, Missouri University of Science and Technology, Rolla, MO 65401, USA, parkjonghy@mst.edu , 1-573-341-4699 


\begin{abstract}
The mechanical instability of the Solid Electrolyte Interphase (SEI) layer in lithium ion (Li-ion) batteries causes significant side reactions resulting in Li-ion consumption and cell impedance rise by forming further SEI layers, which eventually leads to battery capacity fade and power fade. In this paper, the composition-/structure-dependent elasticity of the SEI layer is investigated via Atomic Force Microscopy (AFM) measurements coupled with X-ray Photoelectron Spectroscopy (XPS) analysis, and atomistic calculations. It is observed that the inner layer is stiffer than the outer layer. The measured Young's moduli are mostly in the range of 0.2 to $4.5 \mathrm{GPa}$, while some values above $80 \mathrm{GPa}$ are also observed. This wide variation of the observed elastic modulus is elucidated by atomistic calculations with a focus on chemical and structural analysis. The numerical analysis shows the Young's moduli range from 2.4 GPa to 58.1 GPa in the order of the polymeric, organic, and amorphous inorganic components. The crystalline inorganic component $(\mathrm{LiF})$ shows the highest value $(135.3 \mathrm{GPa})$ among the SEI species. This quantitative observation on the elasticity of individual components of the SEI layer must be essential to analyzing the mechanical behavior of the SEI layer and to optimizing and controlling it.
\end{abstract}




\section{Introduction}

The performance of a Li-ion battery-such as irreversible capacity loss, 1st cycle columbic efficiency, and cycle/calendar life-is closely related to the properties of the solid electrolyte interface (SEI) layer [1-5]. The SEI layer that formed on the negative electrode during the initial few cycles is known as an ionic conductor for lithium but not an electronic conductor, thereby it protects the electrode from further reductive decomposition of the electrolyte during subsequent cycles. It enables a Li-ion battery to maintain its good capacity retention even if the battery operates below the reduction potential of electrolytes. This is the case, however, only if a perfect and stable SEI layer is formed and maintained during the cycling. In reality, the SEI layer does not keep its initial configuration and properties [6]. The aging or degradation process of the SEI layer proceeds to a low extent and at a low rate for the whole cycle/calendar life of Li-ion batteries $[5,6]$. For instance, dissolution/breakdown, conversion, and growth of the SEI layer can occur during prolonged storage and cycling, especially at high temperatures $[3,5,7-9]$. The phenomena cause changes in SEI layer properties, such as composition and morphology, so that the electrons and solvents could be permeable in the defective SEI layer, leading to additional electrolyte decomposition. Continuous decomposition reactions promote further SEI formation or SEI reconstruction, thickening the SEI layer and consuming cyclable lithium-ions. It has been shown that the SEI growth rate slows with time but never stops entirely during long-term storage and cycling [5]. However, if the initially formed SEI layer has desirable and effective properties for SEI stability, the SEI growth rate can be diminished or even come close to stopping entirely, improving the capacity retention of Li-ion batteries. Thus, having an understanding and clarification of the SEI properties in terms of mechanical and chemical aspects is the first important step in achieving the stability of the SEI layer, and eventually the enhancement of the cycle/calendar life of Li-ion batteries.

Many efforts have been made recently to elucidate the structure, morphology, chemical composition, and thickness of the SEI layer on a negative electrode. Inhomogeneous mosaic-type 
or multilayered-type SEI structure models have been proposed based on the SEI layer formation process via 2D surface reduction $[10,11]$. A 3D SEI model, including the intercalation of decomposition products into the graphite interlayer, as well as the attachment of the products to the graphite surface, has been also suggested [12]. Although no consensus on the detailed SEI structure has yet been reached, it is generally accepted that the SEI layer is composed of two distinct layers: a thin, dense layer of inorganic species close to the electrode side, and a thick, porous layer of organic and polymeric compounds close to the electrolyte side. The inorganic species such as lithium fluoride $(\mathrm{LiF})$, lithium carbonate $\left(\mathrm{Li}_{2} \mathrm{CO}_{3}\right)$, and lithium oxide $\left(\mathrm{Li}_{2} \mathrm{O}\right)$ are typically believed to exist as a polycrystalline or crystalline phase, while the organic components such as dilithium ethylene dicarbonate $\left(\left[\mathrm{CH}_{2} \mathrm{OCO}_{2} \mathrm{Li}\right]_{2}, \mathrm{Li}_{2} \mathrm{EDC}\right)$, lithium methyl carbonate $\left(\mathrm{LiOCO}_{2} \mathrm{CH}_{3}\right.$, LiMC), and lithium ethyl carbonate $\left(\mathrm{LiOCO}_{2} \mathrm{C}_{2} \mathrm{H}_{5}, \mathrm{LiEC}\right)$ are commonly reported to present as a form of amorphous structure $[9,13,14]$. In addition, the formation of a long-chain oligomer or polymeric compound such as polyethylene oxide (PEO) has also been reported [14, 15]. The chemical composition of the SEI layer is dependent on the solvents and salts used as the electrolytes. The thickness of the SEI layer has been observed to be in the range of tens to hundreds of nanometers $[13,16]$. Since SEI thickness as well as SEI composition can be influenced by artifacts in measurements and different experimental conditions, the reported values vary from one another.

While numerous studies have been aimed at elucidating SEI formation mechanisms and physical/chemical properties of the SEI layer, relatively little attention has been paid to the mechanical properties of the SEI layer, especially SEI elasticity. During the repeated cycles, the particles of the negative electrode experience volume change, stress, and pressure build-up due to intercalation-induced strain and gas production, which can initiate the physical damage or the instability of the SEI layer as well as the particle surface of the electrode [16, 17]. It has recently been observed that stress change at the surface of a negative electrode is closely related to the SEI layer formation [18]. If a stiff SEI layer is formed on the surface of a negative electrode, the SEI 
layer can be partially broken down due to the stress caused by the intercalation of the Li-ions, which promotes further SEI layer formation by re-exposing the new electrode surface to the electrolyte. This SEI formation and regrowth contributes to a continuous decrease in the capacity of Li-ion batteries. Therefore, an endurable SEI layer is desirable to maintain the mechanical stability of the SEI layer, and to get better adhesion between the electrode and the SEI layer in order to keep the passivation effect.

Recently, a few experimental or computational studies have been conducted to evaluate the elastic properties of the SEI layer. The Atomic Force Microscopy (AFM)-based nanoindentation technique has been used to quantitatively investigate the elastic modulus of the SEI layer. A different surface contact stiffness of the SEI layer on a silicon anode was observed by adding the silane additive in the electrolyte [19]. It was also found that the Young's modulus of the SEI layer on an $\mathrm{MnO}$ anode changes during the SEI formation process [20]. In addition to experimental observations, atomistic simulations were used to predict the elastic modulus of the SEI layer. A molecular dynamics simulation using the ReaxFF potential suggested that ethylene carbonate (EC)-based SEI layer is stiffer than the dimethyl carbonate (DMC)-based SEI layer [21].

As mentioned earlier, the composition and structure of the SEI layer is quite dependent on the system including the anode material, the electrolyte, and the initial formation environment. Furthermore, the mechanical properties of the SEI layer are closely related to the composition and structure of the SEI layer. Previous studies, however, have not provided SEI elasticity based on its chemical composition and structure $[19,20]$. Consequently, a study on the component/structure-dependent SEI elasticity can provide useful guidance for building a more robust SEI layer.

Previous experimental studies have used the probe-based indentation technique to investigate elastic properties of the SEI layer $[19,20]$. Nanoindenter and AFM have been widely used for the probe-based nano-indentation technique to characterize the nano-mechanical 
properties of various materials. However, the technique is comparatively very slow, which makes detailed topographical mapping difficult. In addition, relatively large deformation depths can lead a sample getting damaged, resulting in a poor lateral resolution. The large deformation depth can lead the measured values to be unreliable due to the substrate effect, since SEI layer thickness is typically very thin. It is commonly believed that the indentation depth should be less than a tenth of the film thickness to avoid the substrate effect [22]. The PeakForce Quantitative Nanomechanical (PF-QNM) mode with AFM, which was recently introduced, has allowed quantitative mechanical property mapping at the nanoscale with a high resolution and fast scanning for a range material firmness, from soft to hard [23-29]. It directly controls the maximum normal force to be constant, enabling small load forces with very small deformation depths of a sample, which can minimize the effect of a substrate on the measured modulus [22].

In this work, SEI elasticity is investigated based on a coupled technique: AFM with PFQNM mode and X-ray photoelectron spectroscopy (XPS) measurements. Also, atomistic calculations are conducted to decompose the component and structure effects on the mechanical properties of the constituents of the SEI layer, which is not possible in the measurement.

\section{Methods}

\subsection{Experimental procedure}

\subsubsection{Sample preparation}

A 2032 type-coin cell (MTI Corp.) was assembled in an argon-filled glove box (M Braun). The cell was assembled with a $0.75 \mathrm{~mm}$ thick lithium foil (99.9\%, Alfa Aesar) as the counter electrode (12.7 mm in diameter circle), a highly oriented pyrolytic graphite (HOPG; SPI-

2 grade, $5 \times 5 \times 1 \mathrm{~mm}$, SPI supplies) as the working electrode, and a separator (Celgard 2320, 15.88 in diameter circle) soaked in an electrolyte. The separator was immersed into the electrolyte in an aluminum container for 7 days before use. The electrolyte solution was $1 \mathrm{M}$ lithium hexafluorophosphate $\left(\mathrm{LiPF}_{6} ; \geq 99.99 \%\right.$, Sigma-Aldrich) dissolved in a mixture of ethylene 
carbonate $\left(\mathrm{EC} ; 99 \%,<0.005 \% \mathrm{H}_{2} \mathrm{O}\right.$, Sigma-Aldrich) and dimethyl carbonate (DMC; $\geq 99 \%$, < $0.002 \% \mathrm{H}_{2} \mathrm{O}$, Sigma-Aldrich) with a volume ratio of 1:1. All electrolyte preparation and handling was carried out in an argon-filled glovebox with water and oxygen contents lower than $0.1 \mathrm{ppm}$. The HF content of the electrolyte was less than $80 \mathrm{ppm}$, as determined by a non-aqueous titration method. In order to form the SEI layer on a HOPG sample, the assembled cell was cycled 25 times between $0.01 \mathrm{~V}$ and $1 \mathrm{~V}$ at a constant current density of $50 \mu \mathrm{A} / \mathrm{cm}^{2}$ using a battery test system (Biologic). After cycling, the cell was disassembled in an argon-filled glove box for characterizations. To fully understand the chemical composition of the SEI layer, both the 1st cycled sample and the 25th cycled sample were examined with XPS measurements. The HOPG electrode covered by the SEI layer was rinsed with the DMC solvent for 3 minutes, and was then vacuum-dried overnight to remove any residual salts on the sample.

\subsubsection{Chemical analysis with the X-ray Photoelectron spectroscopy (XPS)}

To analyze the chemical species existing in the SEI layer on the samples, XPS measurements were conducted on a Kratos Axis Ultra X-ray photoelectron spectrometer using a monochromatic Al Ka excitation source $(h v=1486.6 \mathrm{eV})$. The rinsed HOPG was vacuum-sealed in the glove box, and then transferred to the XPS instrument. The sample was briefly exposed to air during the transportation into the analysis chamber. It has been confirmed that a short air exposure-anything less than 2 minutes — does not significantly change the surface chemistry on the sample [30]. The analyzed area of the SEI layer was $300 \times 700 \mu \mathrm{m}^{2}$. The binding energy scale was calibrated from intrinsic hydrocarbon contamination using the $\mathrm{C} 1 \mathrm{~s}$ peak at $285 \mathrm{eV}$. Core spectra were recorded with $20 \mathrm{eV}$ constant pass energy. The fitting of core peaks were performed using the Shirley background correction and Gaussian-Lorentzian curve synthesis (70\% Gaussian, 30\% Lorentzian). Charge neutralization was used in measurements.

\subsubsection{Mechanical analysis with Atomic Force Microscopy (AFM)}


A mechanical property mapping was performed via PeakForce tapping mode using Bruker's Dimension Icon AFM (Bruker, Santa Barbara, CA). PF-QNM measurements were done with silicon probes (TAP525A, Bruker) under ambient conditions. A probe was chosen for measuring both stiff and soft portions of the SEI layer. The deflection sensitivity of the cantilever was measured on a clean sapphire sample for the calibration of the probe. A nominal spring constant was used and then the tip radius was calibrated using a reference sample (highly ordered pyrolytic graphite, Bruker) with a known elastic modulus (18 GPa). The tip radius was adjusted until the observed modulus data matched the known modulus value. After calibrating the probe, topology and elastic modulus images were collected over a $2 \times 2 \mu \mathrm{m}^{2}$ area at a resolution of 512 pixels $\times 512$ pixels. The line scanning rate was set to $0.5 \mathrm{~Hz}$. Each set of Young's modulus measurements on the sample is based on $512 \times 512$ force-separation curves. To prevent damage to the SEI layer formed on the surface of the HOPG, the $2 \mathrm{nN}$ tip force was applied to obtain the elastic modulus map before the scratch. The tip force was then increased to $100 \mathrm{nN}$ to peel off the outer part of the SEI layer, which consists mostly of organic and polymeric species. After the scratch, the $2 \mathrm{nN}$ tip force was set again to acquire the elastic modulus map for the scratched area. The PF-QNM measurement was performed in three different region of the sample. The Young's modulus of the SEI layer was determined by fitting the Derjaguin-Muller-Toporov (DMT) model to the retracting curves of the obtained force-separation curves, as shown in Fig 1. According to the DMT model, the force that describes the tip-surface interaction behavior can be expressed as [31]:

$$
\mathrm{F}-\mathrm{F}_{\mathrm{adh}}=4 / 3 \mathrm{E}^{*} \sqrt{\mathrm{R}\left(\mathrm{d}-\mathrm{d}_{0}\right)^{3}}
$$

where $\mathrm{F}$ is the tip-sample interaction force, $\mathrm{F}_{\text {adh }}$ is the adhesion force during the contact, $\mathrm{E}^{*}$ is the reduced elastic modulus obtained from the DMT fit, $\mathrm{R}$ is the tip end radius, and $\mathrm{d}-\mathrm{d}_{0}$ is the deformation of the sample. The Young's modulus of the sample can be derived using the equation:

$$
\mathrm{E}^{*}=\left[\left(1-v_{\mathrm{s}}^{2}\right) / \mathrm{E}_{\mathrm{s}}+\left(1-v_{\text {tip }}^{2}\right) / \mathrm{E}_{\mathrm{tip}}\right]^{-1}
$$


where $\mathrm{E}_{\mathrm{s}}$ is the Young's modulus of the sample, $v_{\mathrm{s}}$ is the Poisson's ratio of the sample, $v_{\text {tip }}$ is the Poisson's ratio of the probe, and $\mathrm{E}_{\text {tip }}$ is the Young's modulus of the probe. In the PF-QNM measurement, the second term of the above equation was neglected, based on the assumption that $\mathrm{E}_{\mathrm{s}} \ll \mathrm{E}_{\mathrm{tip}}$. The Poisson's ratio of the sample was assumed to be equal to 0.3. The maps obtained using these methods were post-processed with NanoScope Analysis software (Bruker).

\subsection{Computational procedure}

To predict the elastic properties of each SEI layer component, the COMPASS (Condensed-phase Optimized Molecular Potentials for Atomistic Simulation Studies) force field was used as potential functional parameters due to its high accuracy in predicting the condensedphase properties for a broad range of organic, inorganic, and polymeric materials [32]. It has been shown that the COMPASS force field is capable of accurately predicting the elastic properties of organic and polymeric materials [33-36]. With the COMPASS force field, the solubility of lithium salts (organic and inorganic materials) found in the SEI layer was also calculated, showing trends similar to those in experimental observations [9]. For further validation of the force field, a lattice constant and a bulk modulus of crystalline inorganic materials were first compared with available experimental values as well as values of Density Functional Theory (DFT) calculations in the present study.

For the inorganic SEI layer component, both crystalline and amorphous structures were generated for the calculations. However, only amorphous structures were considered for the organic and polymeric SEI layer components, since the organic and polymeric species in the SEI layer have been observed to exist as an amorphous phase [37-39]. Based on our XPS results, LiF and $\mathrm{Li}_{2} \mathrm{CO}_{3}$ were observed as the main inorganic components, thus these two components were considered in the numerical calculations. The initial unit cells of $\mathrm{LiF}$ and $\mathrm{Li}_{2} \mathrm{CO}_{3}$ crystal structures were imported from the available crystallographic data [40, 41], while amorphous structures were generated using the Amorphous Cell module of the Material Studio software 
package (version 6.0, Accelrys Inc.). The size of each simulation cell was in the range of $20 \AA$ to $30 \AA$, depending on the types of SEI layer components. The generated structure was first subjected to a geometry optimization, followed by the isobaric-isothermal (NPT) dynamics at $10^{5} \mathrm{~Pa}$ and $298 \mathrm{~K}$ for $1 \mathrm{~ns}$ in order to equilibrate the structure. The Nose-Hoover thermostat and Berdensen barostat were used for the NPT ensemble. Finally, a 200-ps production run was conducted to calculate the properties of the structure. To get the average values of properties, ten equilibrated structures were chosen in the production run. The Ewald summation was used to compute the non-bonded interactions, such as van der Waals and electrostatic interactions.

For the calculation of the elastic properties, the static approach with constant strains was employed [42]. This methodology has been adopted as a useful approach for estimating the elastic properties of various materials [42-46]. For each equilibrated configuration, the maximum strain amplitude was set to 0.003 so that the minimized structure was strained under a set of 12 deformations (three pairs of uniaxial tension/compression and three pairs of pure shear). The strained structure was then re-minimized following each deformation. The internal stress tensor was then obtained from the analytically calculated virial expression as follows:

$$
\boldsymbol{\sigma}=\frac{1}{V_{0}} \sum_{i}\left[-m_{i} \mathbf{v}_{i} \otimes \mathbf{v}_{i}+\frac{1}{2} \sum_{j \neq i} \mathbf{r}_{i j} \otimes \mathbf{f}_{i j}\right]
$$

where index $i$ runs over all atoms 1 through $\mathrm{N}$ (total number of atoms), $m_{i}, \mathbf{v}_{i} m_{i}$ and $v_{i}$ are the mass and velocity of atom $i, \mathbf{r}_{i j}$ is the relative position vector between atom $i$ and atom $j, \mathbf{f}_{i j}$ denotes the force acting on atom $i$ by atom $j, V_{o}$ is the undeformed system volume, and $\otimes$ is the cross product. The elastic stiffness coefficients were finally determined by estimating the first derivatives of the stress with respect to strain.

$$
\mathrm{C}_{\mathrm{ijkl}}=\partial \boldsymbol{\sigma}_{\mathrm{ij}} / \partial \boldsymbol{\varepsilon}_{\mathrm{kl}}
$$

where $\mathbf{C}$ is the elastic stiffness tensor, $\boldsymbol{\sigma}$ is the stress tensor, and $\boldsymbol{\varepsilon}$ is the strain tensor. The elastic constants were then averaged over ten equilibrated configurations. In order to predict the elastic 
aggregate properties of the bulk (B) and shear modulus (G), the Voigt-Reuss-Hill (VRH) approximation method was used by averaging the elastic constants of the single crystal over all orientations [47].

$$
\begin{gathered}
\mathrm{B}_{\text {Voigt }}=1 / 9\left[\mathrm{C}_{11}+\mathrm{C}_{22}+\mathrm{C}_{33}+2\left(\mathrm{C}_{12}+\mathrm{C}_{13}+\mathrm{C}_{23}\right)\right] \\
\mathrm{B}_{\text {Reuss }}=\left[\mathrm{S}_{11}+\mathrm{S}_{22}+\mathrm{S}_{33}+2\left(\mathrm{~S}_{12}+\mathrm{S}_{13}+\mathrm{S}_{23}\right)\right]^{-1} \\
\mathrm{G}_{\text {Voigt }}=1 / 15\left[\mathrm{C}_{11}+\mathrm{C}_{22}+\mathrm{C}_{33}-\mathrm{C}_{12}-\mathrm{C}_{13}-\mathrm{C}_{23}+3\left(\mathrm{C}_{44}+\mathrm{C}_{55}+\mathrm{C}_{66}\right)\right] \\
\mathrm{G}_{\text {Reuss }}=15\left[4\left(\mathrm{~S}_{11}+\mathrm{S}_{22}+\mathrm{S}_{33}-\mathrm{S}_{12}-\mathrm{S}_{13}-\mathrm{S}_{23}\right)+3\left(\mathrm{~S}_{44}+\mathrm{S}_{55}+\mathrm{S}_{66}\right)\right]^{-1}
\end{gathered}
$$

The Hill value is defined as the average of values obtained by the other two approaches, namely, $\mathrm{B}_{\text {Hill }}=\left(\mathrm{B}_{\text {Voigt }}+\mathrm{B}_{\text {Reuss }}\right) / 2$ and $\mathrm{G}_{\text {Hill }}=\left(\mathrm{G}_{\text {Voigt }}+\mathrm{G}_{\text {Reuss }}\right) / 2$ [48]. From the averaged bulk and shear modulus, the Young's modulus (Y) of an aggregate can be estimated based on the bulk modulus and the shear modulus as follows [49].

$$
\mathrm{Y}=9 \mathrm{~B}_{\text {Hill }} \mathrm{G}_{\text {Hill }} /\left(\mathrm{G}_{\text {Hill }}+3 \mathrm{~B}_{\text {Hill }}\right)
$$

Here, we used the value obtained by the Hill approach to represent the bulk and shear modulus of each SEI layer component.

\section{Results and discussion}

\subsection{Experimental results}

\subsubsection{Chemical components of the SEI layer on a HOPG}

To identify the chemical composition of the SEI layer formed on a HOPG surface, an XPS analysis was conducted. Figure 2 shows high-resolution XPS spectra of the SEI layer formed on the HOPG basal plane after the 25 th cycle. The graphite peak at $284.3 \mathrm{eV}$ in the $\mathrm{C} 1 \mathrm{~s}$ spectrum is not identified, indicating that the HOPG surface is fully covered by the SEI layer. The chemical composition of the SEI layer consists of various chemical species, including solvent reduction/decomposition products, polymeric species, and salt reduction/decomposition products. 
Based on the peak fitting of the $\mathrm{C} 1 \mathrm{~s}$ spectrum, five peaks can be assigned. The peak at $285 \mathrm{eV}$, assigned to $\mathrm{C}-\mathrm{C}, \mathrm{C}-\mathrm{H}$ bonds, is attributed to the intrinsic hydrocarbon, alkanes $(\mathrm{C}-\mathrm{H})$, and polymers which consist of hydrocarbons $\left(-\mathrm{CH}_{2}-\mathrm{CH}_{2}\right.$ - type bonds) [50-55]. The second peak at near $286.3 \mathrm{eV}$ corresponding to $\mathrm{C}-\mathrm{O}$ bonds associates with oxygen-containing polymeric species such as polyethylene oxide PEO (- $\left.\mathrm{CH}_{2}-\mathrm{CH}_{2}-\mathrm{O}-\right) \mathrm{n}$ and lithium alkyl carbonates $\mathrm{ROCO}_{2} \mathrm{Li}$ $[30,50,52,55]$. The two peaks in the vicinity of $287.3 \sim 288.5 \mathrm{eV}$ originate from the contribution of the $\mathrm{ROCO}_{2} \mathrm{Li}[30,50,55]$. The lithium alkyl carbonates $\mathrm{ROCO}_{2} \mathrm{Li}$ are formed due to the reduction of solvents, and have widely been considered to be one of the main components of the SEI layer on negative electrodes. The formation of PEO oligomers has also been suggested by a ring-opening mechanism of the solvent $\mathrm{EC}$, leading to the formation of $\mathrm{CO}_{2}[14,15]$. In $\mathrm{O} 1 \mathrm{~s}$ spectrum, the broad asymmetric peak is due to a convolution of $\mathrm{Li}_{2} \mathrm{CO}_{3}(531.5 \mathrm{eV})$ and $\mathrm{ROCO}_{2} \mathrm{Li}$ $(532.3 \mathrm{eV})$. A shoulder at $533.9 \mathrm{eV}$ originates from PEO oligomers and a portion of $\mathrm{ROCO}_{2} \mathrm{Li}$ $[30,50]$. The small peak near $528.7 \mathrm{eV}$ corresponds to the formation of $\mathrm{Li}_{2} \mathrm{O}$, which is known as a consequence of $\mathrm{Li}_{2} \mathrm{CO}_{3}$ decomposition or trace amounts of water in the electrolyte [50,51, 54, 56]. The presence of $\mathrm{Li}_{2} \mathrm{O}$ in the SEI layer remains a matter of debate. Previous study reported that the observed $\mathrm{Li}_{2} \mathrm{O}$ could be an artifact of the sputtering process rather than a true SEI component [56]. However, there is an agreement that the $\mathrm{Li}_{2} \mathrm{O}$ is not a major component of the SEI layer. In this work, a small amount of $\mathrm{Li}_{2} \mathrm{O}$ is found in the SEI layer without any sputtering process.

Besides the solvent reduction products, salt reduction or decomposition compounds are clearly detected as a portion of SEI layer. The inorganic $\mathrm{LiF}(685.5 \mathrm{eV}$ in $\mathrm{F} 1 \mathrm{~s}, 56 \mathrm{eV}$ in $\mathrm{Li} 1 \mathrm{~s})$ and residue $\mathrm{LiPF}_{6}$ - and/or its reduction products $\mathrm{Li}_{\mathrm{x}} \mathrm{PF}_{\mathrm{y}}(687.5 \mathrm{eV}$ in $\mathrm{F} 1 \mathrm{~s}$ )—are also formed at the surface [30, 52-54]. The strong peak at $137.3 \mathrm{eV}$ in the $\mathrm{P} 2 \mathrm{p}$ supports that salt residues or its reduction products are formed considerably in the SEI layer. A small amount of $\mathrm{Li}_{\mathrm{x}} \mathrm{PF}_{\mathrm{y}} \mathrm{O}_{\mathrm{z}}(134.2$ $\mathrm{eV}$ in the P 2p) due to the hydrolysis of $\mathrm{LiPF}_{6}$ is observed in the SEI layer as well [30]. 
In order to obtain more clear information on chemical composition of the formed SEI layer after the 25th cycle, the 1st cycled HOPG was compared to the 25th cycled HOPG, as shown in Fig. 3. The main difference is that an undetected peak at $289.7 \mathrm{eV}$ is visible after the $25^{\text {th }}$ cycle, indicating the formation of the lithium carbonate $\mathrm{Li}_{2} \mathrm{CO}_{3}$ during the cycling (Fig. 3a). This result suggests that less stable compounds partially converted to the $\mathrm{Li}_{2} \mathrm{CO}_{3}$ over repeated cycling. It has been previously observed that the metastable $\mathrm{ROCO}_{2} \mathrm{Li}$ can decompose to form the more stable $\mathrm{Li}_{2} \mathrm{CO}_{3}$ at high temperature and over repeated cycling [30, 57]. It is supported by an observation that the intensity of dominant peaks associated with $\mathrm{ROCO}_{2} \mathrm{Li}$ and $\mathrm{PEO}$ (near 286 $287 \mathrm{eV}$ in Fig. 3a) decreases after the 25th cycle. Compared to the $\mathrm{Li}_{2} \mathrm{CO}_{3}$, the inorganic $\mathrm{LiF}$ (685.5 eV in Fig. 3b), which is observed in the SEI layer formed after the 1st cycle, is still seen after the 25th cycle (Fig. 3b). However, the significant increase of peak intensity at $685.5 \mathrm{eV}$ after the 25 th cycle indicates that the extent of the $\mathrm{LiF}$ considerably increases over repeated cycling. Alternatively, a considerable amount of the $\mathrm{LiF}$ is included in the SEI layer after the 25th cycle compared to the SEI layer formed after the 1st cycle. Consequently, it is expected that the SEI layer formed after the 25 th cycle is stiffer than after the 1 st cycle. As the SEI layer after 25 cycles is thicker than that after 1 st cycle, it implies that the inorganic LiF considerably exists in the outer part as well as the inner part of the SEI layer. It has been suggested that the LiF widely distributes throughout the SEI layer as a form of isolated crystallites rather than a solid layer $[55,56]$. In addition, the peak $(688 \mathrm{eV})$ related to the salt residue $\mathrm{LiPF}_{6}$ shifts to the lower binding energy $(687.5 \mathrm{eV})$ due to the formation of the degradation products $\mathrm{Li}_{\mathrm{x}} \mathrm{PF}_{\mathrm{y}}$ after the 25th cycle [53]. That is, the salt residue and reduction products are also distributed throughout the SEI layer, thereby those species can be found on the surface. Therefore, it is expected that these stiff components such as $\mathrm{Li}_{2} \mathrm{CO}_{3}, \mathrm{LiF}, \mathrm{LiPF}_{6}, \mathrm{Li}_{\mathrm{x}} \mathrm{PF}_{\mathrm{y}}$, and $\mathrm{Li}_{\mathrm{x}} \mathrm{PF}_{\mathrm{y}} \mathrm{O}_{\mathrm{z}}$ significantly contributes to the elastic modulus of the SEI layer.

\subsubsection{Elastic modulus of the SEI layer}


Figure 4 shows the measured DMT modulus maps with the corresponding cross-section plots using PeakForce QNM imaging mode for a fresh HOPG (Fig. 4a), a 25-time cycled HOPG before scratching (Fig. 4b), and the same sample as in Fig. 4b but scratched (Fig. 4c). As shown in Fig. $4 \mathrm{a}$, the elastic modulus of the fresh HOPG basal plane is about $10.9 \pm 2.9 \mathrm{GPa}$, which is in good agreement with the reported Young's modulus of $10.5 \mathrm{GPa}$ that was found in the literature [58]. Although the elastic modulus is quite consistent over the scan area, a slight variation still exists in the observed elastic modulus. This variation may come from the surface roughness and defects of the HOPG samples. The dulled or contaminated tip while scanning the surface may also contribute to the variation.

As confirmed by the XPS measurements (Section 3.1.1), an SEI layer is formed after cycling, and the formed SEI layer in the cycled HOPG consists of various chemical components. Figure $4 \mathrm{~b}$ shows a change of modulus after the sample is cycled; a lower elastic modulus is observed compared to the fresh HOPG. The average elastic modulus measured in the entire scan area $\left(2 \times 2 \mu \mathrm{m}^{2}\right)$ shows $3.8 \pm 5.6 \mathrm{GPa}$. The observed large deviation is mainly due to the observed inhomogeneous elastic modulus as well as the non-uniform SEI surface. In the image, the bright (white color) spots indicate a relatively high elastic modulus compared to the dark (brown color) area. Our XPS results show that the SEI layer is composed of organic/polymeric compounds, inorganic compounds, and salts residues. In general, inorganic materials have higher elastic moduli compared to organic materials, thus it is expected that the higher modulus is associated with partially exposed inorganic compounds through porous organic outer layer, and $\mathrm{LiPF}_{6}$ salt residues and its decomposition products $\left(\mathrm{LiF}, \mathrm{Li}_{x} \mathrm{PF}_{\mathrm{y}}\right.$, and $\left.\mathrm{Li}_{\mathrm{x}} \mathrm{PF}_{\mathrm{y}} \mathrm{O}_{z}\right)$ on the surface. It is supported by the previous XPS results (Section 3.1.1): the salt decomposition species (mainly the $\mathrm{LiF}$ ) exist in a significant way on the surface after 25 cycles. The lower modulus can be explained by the existence of organic and polymeric species. In order to further confirm our observation, the outer portion of the SEI layer is scraped off by increasing the tip force during the scan. Figure 4c shows the elastic modulus map and corresponding cross-section profile of the SEI layer after the 
scratch. The average elastic modulus in the whole scan area increases to $8.3 \pm 11.5 \mathrm{GPa}$. As mentioned, the large deviation is due to distinct difference in the elastic modulus (bright vs. dark) within the scan area. The DMT modulus plots at the same cross-section line (Fig. 4b vs. Fig. 4c) clearly prove that the elastic modulus significantly increases after the scratch. The increased modulus is related to the increased amounts of inorganic component portions of the SEI layer after the scratch. It has been known that dense inorganic components that are present at the inner portion of the SEI layer close to the electrode and porous organic/polymeric species mainly consist of the outer portion of the SEI layer. During the scratch, it seems that soft organic and polymeric species are easily removed, revealing more inorganic compounds that exist at the inner part of the SEI layer. Note that the organic/polymeric species are still observed in some regions, suggesting that one scratch is not enough to entirely remove the outer part of SEI layer. Only one scratch was conducted to minimize the effect of the dulled or contaminated tip on the modulus measurements. The histograms illustrated in Fig. 5 provide a clear difference in the elastic modulus before (Fig. 5a) and after the scratch (Fig. 5b), corresponding to the maps shown in Fig. $4 \mathrm{~b}$ and Fig. 4c, respectively. Before the scratch, the measured elastic modulus of the SEI layer is mostly in the range from 0.2 to $4.5 \mathrm{GPa}$, showing around $84 \%$ of the elastic modulus values below 4.5 GPa. After the scratch, the amount of species exhibiting low elastic moduli decreases, while the amount of species with high elastic moduli increases, showing around $47 \%$ of the elastic modulus values above 4.5 GPa. It indicates that SEI compounds other than organic and polymeric species in abundance on the surface, which implies the more exposure of inorganic species due to the scratch.

On zooming into the inorganic region that shows a considerable number of high elastic moduli (Dotted square area A in Fig. 4c), the histogram indicates that the modulus is mainly in the range from 20 to $85 \mathrm{GPa}$, as shown in Fig. 6a. The histogram of area B (Fig. 6b) shows $1.0 \pm$ 0.2 GPa, which is in a similar range of polymeric and organic phase materials [25, 26,59-62]. Note that a wider range of elastic moduli is measured at the region identified as inorganic species 
than the region of the organic and polymeric phase region. This may come from two reasons related to the chemical and structural characteristics of the inorganic components of the SEI layer. First, a wide variance in the elastic moduli of the inorganic components $\left(\mathrm{LiF} \mathrm{Li}_{\mathrm{x}} \mathrm{PF}_{\mathrm{y}}, \mathrm{Li}_{\mathrm{x}} \mathrm{PF}_{\mathrm{y}} \mathrm{O}_{\mathrm{z}}\right.$, $\mathrm{Li}_{2} \mathrm{CO}_{3}$, and salt residues) can contribute to the observed wide range of elastic moduli. Second, the crystallinity's orientation may result in the broad range of inorganic species' elastic moduli. It has been reported that the elastic properties of various materials strongly depend on its degree of crystallinity and crystal orientation [62-65]. The elastic modulus versus the crystallinity linear relationship has been observed in polyethylene [63]. A DFT calculation has shown that a variation of Young's modulus can be around $70 \mathrm{GPa}$ depending on the angle between the crystal c-axis and the direction of strain [65]. In the literature, it has been reported that the organic components exist as an amorphous phase, while the inorganic components form a (poly)crystalline phase. However, it is still possible that a portion of the inorganic SEI layer exists as a form of an amorphous phase during the SEI formation and evolution process. In the next session, this structure-dependent SEI elasticity is discussed.

\subsection{Computational results}

\subsubsection{Structure-dependent SEI layer elasticity}

Based on our XPS measurements and other literature, $\mathrm{LiF}$ and $\mathrm{Li}_{2} \mathrm{CO}_{3}$ are recognized as the main inorganic components of the SEI layer. These components are chosen to explore the structure-elastic property relationship of the individual inorganic SEI layer components. Table 1 lists the cell lattice parameters of the equilibrated crystalline structures calculated in this work, including experimental data and other calculations for comparison [41, 66-69]. The cell lattice

parameters of the equilibrated crystalline structures in this work are quite close to the experimental values, showing less than a $6 \%$ deviation from the experimental values. Depending on the calculation methods or the force field used, the calculated values in the literature vary up to around $7 \%$ of each other, as shown in Table 1 . To evaluate whether the equilibrated structures 
represent the characteristics of a crystalline or an amorphous structure, the total pair distribution function, $\mathrm{g}(\mathrm{r})$, which describes the distribution of the distances between pairs of atoms in a given volume, is plotted in Fig. 7. Compared to the equilibrated crystalline structures showing an existence of long-range order, the equilibrated amorphous structures show a short-range order because they show the presence of peaks over a much shorter distance compared to the crystalline structures. Therefore, the equilibrated amorphous structures do a good job of reproducing the features of an amorphous solid.

In order to investigate the effect of the crystallinity of the SEI layer components on the elastic properties, the estimated bulk, shear modulus, and B/G ratio values of the SEI inorganic components are calculated, as shown in Table 2. The calculated bulk modulus of crystalline LiF (89.4 GPa) is within the other calculated values that vary from 60 to $95 \mathrm{GPa}$, and is close to the experimental values of $69.9,73.0 \mathrm{GPa}[67,70]$. The calculated bulk modulus of crystalline $\mathrm{Li}_{2} \mathrm{CO}_{3}(50.5 \mathrm{GPa})$ also shows good agreement with other calculated values in the range of 41.7 to 55.5 GPa [69]. Based on Pugh's criterion (B/G ratio) of a brittleness material [71], the crystalline LiF behaves in a brittle manner $(\mathrm{B} / \mathrm{G}<1.75)$, while the crystalline $\mathrm{Li}_{2} \mathrm{CO}_{3}$ is a ductile material (>1.75). Other theoretical calculations based on DFT also predict that the monoclinic $\mathrm{Li}_{2} \mathrm{CO}_{3}$ is a ductile material, showing B/G values above 2 [69]. Generally, the bulk modulus of an amorphous structure has a lower value than that of the crystalline structure of the same material. For the amorphous phase, the bulk moduli of $\mathrm{LiF}$ and $\mathrm{Li}_{2} \mathrm{CO}_{3}$ are 45.5 and $43.1 \mathrm{GPa}$, respectively. Similar trends can be found in the shear modulus and the Young's modulus. Figure 8 clearly shows the structure dependence of the Young's modulus. The crystalline LiF shows $135.3 \mathrm{GPa}$, which is close to the experimental value ( $125 \mathrm{GPa})$ [72], while the amorphous LiF has a considerably lower value of $58.1 \mathrm{GPa}$. Similarly, the Young's modulus of crystalline $\mathrm{Li}_{2} \mathrm{CO}_{3}$ (54.8 GPa) is also quite higher than the amorphous phase of $\mathrm{Li}_{2} \mathrm{CO}_{3}(36.2 \mathrm{GPa})$. Note that the influence of the microstructure on the elastic properties is much larger for the LiF than for the $\mathrm{Li}_{2} \mathrm{CO}_{3}$. The change in the structure of the LiF not only decreases the modulus, but also changes 
the brittle and ductile behavior of the $\mathrm{LiF}$ material. According to the $\mathrm{B} / \mathrm{G}$ ratio shown in Table 2, the $\mathrm{LiF}$ component behaves as a ductile material under an amorphous state, while it behaves as a brittle material under a crystalline state. However, the $\mathrm{Li}_{2} \mathrm{CO}_{3}$ component exists as a ductile material regardless of its being in a crystalline or amorphous phase.

Since an SEI layer is not homogenous and it is formed on a composite anode material with crystalline (graphite) and amorphous (binder) features, pure $\mathrm{Li}_{2} \mathrm{CO}_{3}$ and $\mathrm{LiF}$ with crystalline features might not be formed or changed during the SEI formation and growth. It has been observed that pure $\mathrm{Li}_{2} \mathrm{CO}_{3}$ with a crystalline feature can be changed to an amorphous feature of $\mathrm{Li}_{2} \mathrm{CO}_{3}$ as the $\mathrm{Li}_{2} \mathrm{CO}_{3}-\mathrm{Al}_{2} \mathrm{O}_{3}$ composite solid electrolyte is synthesized due to chemical reactions between the composite components [73]. Several chemical reactions such as salt/solvent decompositions and reactions between components are involved in SEI formation and growth. Thus, it is possible for the inorganic $\mathrm{LiF}$ and $\mathrm{Li}_{2} \mathrm{CO}_{3}$ to exist as forms of a polycrystalline or even amorphous phase, rather than a pure crystalline phase. It has also been found that thin film LiF with the preferred orientation changes to a completely random structure as it grows on an amorphous substrate [74]. Thus, the SEI growth on the composite anode and the inhomogeneous SEI layer itself could make it difficult to form well-ordered structures, even though pure $\mathrm{LiF}$ and $\mathrm{Li}_{2} \mathrm{CO}_{3}$ show high crystalline features. Consequently, the observed wide range of the elastic modulus - especially at the inorganic regions compared to organic regions (Fig. 4c)—can be explained by the atomistic calculation results in this section. If the inorganic components can exist as different crystal structures in the SEI layer, the inorganic SEI layer shows a large variation of the elastic modulus.

\subsubsection{Component-dependent SEI layer elasticity}

Figure 9 shows the atomic structure of each SEI layer component used in the calculations. These components have been known as the main chemical species typically found in the SEI layer in the EC/DMC-based electrolyte. Our XPS results also confirm that the formed SEI 
layer on the HOPG surface mainly consists of these organic, polymeric, and inorganic chemical components, such as $\mathrm{Li}_{2} \mathrm{EDC}, \mathrm{LiEC}, \mathrm{LiMC}, \mathrm{PEO}, \mathrm{LiF}$, and $\mathrm{Li}_{2} \mathrm{CO}_{3}$.

The calculated bulk (B) and shear (G) modulus of each amorphous organic/polymeric component with its $\mathrm{B} / \mathrm{G}$ value are listed in Table 3 . The bulk modulus of organic/polymeric species ranges from $2.5 \mathrm{GPa}$ to $18.9 \mathrm{GPa}$ in the order of $\mathrm{PEO}<\mathrm{LiEC}<\mathrm{LiMC}<\mathrm{Li}_{2} \mathrm{EDC}$, which is similar to the order in the previous work [21]. The discrepancy between the calculated and measured values may be due to the simulations performed on defect-free materials or experimental assumptions, such as Poisson's ratio and the DMT model. Note that the calculated values of organic/polymeric species are considerably lower than those of inorganic species (Table 2) regardless of the crystal structure. The shear modulus follows the same order as the bulk modulus $\left(\mathrm{PEO}<\mathrm{LiEC}<\mathrm{LiMC}<\mathrm{Li}_{2} \mathrm{EDC}\right.$ ). The organic species of the SEI layer have a higher elastic modulus than the polymeric PEO of the SEI layer. Among organic species, the elastic modulus of $\mathrm{Li}_{2} \mathrm{EDC}$, which is known as a primary component in the EC-based SEI layer, is relatively high compared to other organic species. One of the main decomposition products in the DMC-based SEI layer, LiMC, also has a lower modulus than the $\mathrm{Li}_{2} \mathrm{EDC}$. According to our simulation results, it seems that the EC-based SEI layer is stiffer than the DMC-based SEI layer. The trend is in a good agreement with the previous observation [21]. As expected, all organic and polymeric species of an SEI layer show ductile behaviors based on the calculated B/G values (> 1.75). Specifically, the organic species ( $\mathrm{Li}_{2} \mathrm{EDC}$ and $\left.\mathrm{LiMC}\right)$ of $\mathrm{EC}$ and $\mathrm{DMC}$ decomposition products are less ductile than the polymeric PEO.

Figure 10 compares the Young's modulus of each SEI layer component constructed as an amorphous structure. The figure illustrates the component dependence of the SEI elasticity. It clearly shows that the SEI elasticity is linked with the chemical composition of the SEI layer. The Young's moduli of different SEI components range from $2.4 \mathrm{GPa}$ to $58.1 \mathrm{GPa}$ in order of the polymeric, organic, and inorganic components, specifically $\mathrm{PEO}<\mathrm{LiEC}<\mathrm{LiMC}<\mathrm{Li}_{2} \mathrm{EDC}<$ $\mathrm{Li}_{2} \mathrm{CO}_{3}<\mathrm{LiF}$. The inorganic $\mathrm{LiF}$ is the stiffest component of the SEI layer, while the polymeric 
PEO is the most flexible part of the SEI layer. Even if the inorganic components are assumed to be amorphous, a considerable difference is still observed between the Young's moduli of inorganic and organic/polymeric species. The elasticity difference between organic layers and inorganic layers in the SEI layer is even more significant if inorganic species exist as crystalline or polycrystalline phase. Therefore, the extremely high modulus values observed in our experiments are possibly due to crystalline $\mathrm{LiF}$ and other crystalline inorganic species.

The flexible organic/polymeric layer that exists at the outer part of the SEI layer is possibly less affected by a large strain due to volume changes during intercalation and deintercalation. On the other hand, the stiff inorganic layer that forms at the inner part of the SEI layer would be difficult to withhold from large strain, causing mechanical degradation of the inorganic inner layer. Especially, the inner part that consists of $\mathrm{LiF}$ species rather than $\mathrm{Li}_{2} \mathrm{CO}_{3}$ is likely to experience a failure or cracking of the SEI layer due to the induced stress. For this reason, as an example, for a silicon anode with such a huge volume change, $\mathrm{Li}_{2} \mathrm{CO}_{3}$ would be a more favorable component than $\mathrm{LiF}$ as an inorganic layer keeping a good passivation characteristic. In a similar way, as an organic layer, the formation of polymeric PEO rather than other organic species is more effective for SEI elasticity, building a more flexible SEI layer. Therefore, it is important to control SEI chemical composition to achieve desirable SEI elasticity, especially an electrode with a large change in volume.

\section{Conclusions}

In this work, the SEI elasticity has been studied both experimentally and computationally. To characterize the SEI elasticity, the SEI layer formed on a HOPG electrode in a $\mathrm{LiPF}_{6} /$ EC+DMC electrolyte has been investigated using PF-QNM and atomistic calculations. Both experimental and computational results have shown that SEI elasticity is strongly affected by the SEI chemical composition. We have found significant differences in the SEI elastic properties between organic/polymeric components and inorganic components of SEI layer. Experimental 
results have revealed that the inner layer contains considerably more of the stiff species than the outer layer does. Computational results have shown the component and its structure dependence of SEI elasticity. The elasticity of each main SEI component has been determined, showing stiffer behavior in the order of $\mathrm{LiF}>\mathrm{Li}_{2} \mathrm{CO}_{3}>\mathrm{Li}_{2} \mathrm{EDC}>\mathrm{LiMC}>\mathrm{LiEC}>\mathrm{PEO}$. In addition, it has also been shown that the elasticity of SEI inorganic component varies significantly depending on its crystal structure. In particular, the elasticity of $\mathrm{LiF}$ is more easily affected than $\mathrm{Li}_{2} \mathrm{CO}_{3}$ by change in the crystal structure.

The findings from this work can be used in controlling the SEI layer to minimize damage to the SEI layer. The mechanical stability (adhesion, elasticity, etc.) of the SEI layer can be achieved by changing formation conditions and electrolytes (salts, solvents, and additives). For instance, the formation of an inorganic layer with an amorphous feature, and of a PEO polymeric layer rather than an EC- or DMC-based organic layer would be desirable for forming a flexible SEI layer. This strategy focused on mechanical stability would be critically important for new promising materials like silicon in which the main challenge is to mitigate the mechanical instability.

\section{Acknowledgements}

The authors acknowledge the support of this project provided by the U.S. Department of Energy, with additional sponsorship by the General Motors/University of Michigan Advanced Battery Coalition for Drivetrains.

\section{Figure Captions}

Figure 1. Schematic diagram of a force vs. separation curve in the PeakForce tapping mode Figure 2. F 1s, O 1s, C 1s, P 2p, Li 1s XPS high-resolution spectra of the 25th cycled HOPG 
Figure 3. Comparison of the 1st cycled and the 25th cycled HOPG: (a) C 1s XPS spectrum, (b) F 1s XPS spectrum

Figure 4. Representative maps of DMT modulus with corresponding cross sections: (a) HOPG before cycling, (b) SEI layer formed on HOPG after 25 cycles, (c) SEI layer formed on HOPG after scratching

Figure 5. Histograms of DMT modulus: (a) SEI layer before scratching, (b) HOPG after scratching

Figure 6. Histograms of DMT modulus: (a) The dotted square area A in Fig. 3c (Inorganic region), (b) The dotted square area B in Fig. 3c (Organic/polymeric region)

Figure 7. Total pair distribution function, g(r): (a) Crystalline structure (c) Amorphous structure Figure 8. The predicted Young's modulus of inorganic SEI component with different crystal structures (Crystalline vs. Amorphous)

Figure 9. The chemical structures of SEI components (Organic, polymeric, and inorganic species) used in simulations.

Figure 10. The predicted Young's modulus of an individual SEI component 


\section{Table Captions}

Table 1. Experimental and calculated lattice parameters ( $a, b$, and c in $\AA$ ) and angle $\left(\beta\right.$ in ${ }^{\circ}$ ) of inorganic crystalline species

Table 2. Predicted elastic properties (B, $\mathrm{G}$ in $\mathrm{GPa}$ ) of inorganic $\mathrm{LiF}$ and $\mathrm{Li}_{2} \mathrm{CO}_{3}$ with different crystal structures (Crystalline vs. Amorphous)

Table 3. Predicted elastic properties (B, G in GPa) of main organic and polymeric SEI components 


\section{References}

[1] D. Aurbach, B. Markovsky, I. Weissman, E. Levi, Y. Ein-Eli, Electrochim. Acta, 45 (1999) $67-86$.

[2] R. Yazami, Y.F. Reynier, Electrochim. Acta, 47 (2002) 1217-1223.

[3] M. Inaba, H. Tomiyasu, A. Tasaka, S.K. Jeong, Z. Ogumi, Langmuir, 20 (2004) 1348-1355.

[4] T. Yoshida, M. Takahashi, S. Morikawa, C. Ihara, H. Katsukawa, T. Shiratsuchi, J. Yamaki, J. Electrochem. Soc., 153 (2006) A576-A582.

[5] A.J. Smith, J.C. Burns, X. Zhao, D. Xiong, J.R. Dahn, J. Electrochem. Soc., 158 (2011) A447A452.

[6] J. Vetter, P. Novak, M.R. Wagner, C. Veit, K.C. Moller, J.O. Besenhard, M. Winter, M.

Wohlfahrt-Mehrens, C. Vogler, A. Hammouche, J. Power Sources, 147 (2005) 269-281.

[7] A. Du Pasquier, F. Disma, T. Bowmer, A.S. Gozdz, G. Amatucci, J.M. Tarascon, J.

Electrochem. Soc., 145 (1998) 472-477.

[8] T. Zheng, A.S. Gozdz, G.G. Amatucci, J. Electrochem. Soc., 146 (1999) 4014-4018.

[9] K. Tasaki, A. Goldberg, J.-J. Lian, M. Walker, A. Timmons, S.J. Harris, J. Electrochem. Soc., 156 (2009) A1019-A1027.

[10] A. Zaban, D. Aurbach, J. Power Sources, 54 (1995) 289-295.

[11] E. Peled, D. Golodnitsky, G. Ardel, J. Electrochem. Soc., 144 (1997) L208-L210.

[12] J.O. Besenhard, M. Winter, J. Yang, W. Biberacher, J. Power Sources, 54 (1995) 228-231.

[13] P. Verma, P. Maire, P. Novak, Electrochim. Acta, 55 (2010) 6332-6341.

[14] R. Dedryvere, S. Laruelle, S. Grugeon, L. Gireaud, J.M. Tarascon, D. Gonbeau, J.

Electrochem. Soc., 152 (2005) A689-A696.

[15] H. Tavassol, J.W. Buthker, G.A. Ferguson, L.A. Curtiss, A.A. Gewirth, J. Electrochem. Soc., 159 (2012) A730-A738.

[16] H.L. Zhang, F. Li, C. Liu, J. Tan, H.M. Cheng, J. Phys. Chem. B, 109 (2005) 22205-22211. 
[17] R. Deshpande, M. Verbrugge, Y.-T. Cheng, J. Wang, P. Liu, J. Electrochem. Soc., 159 (2012) A1730-A1738.

[18] H. Tavassol, M.K.Y. Chan, M.G. Catarello, J. Greeley, D.G. Cahill, A.A. Gewirth, J. Electrochem. Soc., 160 (2013) A888-A896.

[19] W. Xu, S.S.S. Vegunta, J.C. Flake, J. Power Sources, 196 (2011) 8583-8589.

[20] J. Zhang, R. Wang, X. Yang, W. Lu, X. Wu, X. Wang, H. Li, L. Chen, Nano Lett., 12 (2012) 2153-2157.

[21] S.-P. Kim, A.C.T. van Duin, V.B. Shenoy, J. Power Sources, 196 (2011) 8590-8597.

[22] H. Cabibil, H. Celio, J. Lozano, J.M. White, R. Winter, Langmuir, 17 (2001) 2160-2166.

[23] P. Trtik, J. Kaufmann, U. Volz, Cem. Concr. Res., 42 (2012) 215-221.

[24] G. Pletikapic, A. Berquand, T.M. Radic, V. Svetlicic, J. Phycol., 48 (2012) 174-185.

[25] M.E. Dokukin, I. Sokolov, Langmuir, 28 (2012) 16060-16071.

[26] T.J. Young, M.A. Monclus, T.L. Burnett, W.R. Broughton, S.L. Ogin, P.A. Smith, Meas. Sci. Technol., 22 (2011).

[27] K. Sweers, K. van der Werf, M. Bennink, V. Subramaniam, Nanoscale Res. Lett., 6 (2011).

[28] P. Schon, K. Bagdi, K. Molnar, P. Markus, B. Pukanszky, G.J. Vancso, Eur. Polym. J., 47 (2011) 692-698.

[29] J. Adamcik, A. Berquand, R. Mezzenga, Appl. Phys. Lett., 98 (2011).

[30] A.M. Andersson, D.P. Abraham, R. Haasch, S. MacLaren, J. Liu, K. Amine, J. Electrochem. Soc., 149 (2002) A1358-A1369.

[31] B.V. Derjaguin, V.M. Muller, Y.P. Toporov, J. Colloid Interface Sci., 52 (1975), 314-326

[32] H. Sun, J. Phys. Chem. B, 102 (1998) 7338-7364.

[33] M. Grujicic, Y.P. Sun, K.L. Koudela, Appl. Surf. Sci., 253 (2007) 3009-3021.

[34] S.S. Jang, W.A. Goddard, III, M.Y.S. Kalani, J. Phys. Chem. B, 111 (2007) 1729-1737.

[35] A. Sturcova, G.R. Davies, S.J. Eichhorn, Biomacromolecules, 6 (2005) 1055-1061.

[36] W.A.W. Hassan, I. Hamerton, B.J. Howlin, PLoS One, 8 (2013). 
[37] P. Poizot, S. Laruelle, S. Grugeon, L. Dupont, J.M. Tarascon, Nature, 407 (2000) 496-499.

[38] S. Chattopadhyay, A.L. Lipson, H.J. Karmel, J.D. Emery, T.T. Fister, P.A. Fenter, M.C. Hersam, M.J. Bedzyk, Chem. Mater., 24 (2012) 3038-3043.

[39] S. Shi, P. Lu, Z. Liu, Y. Qi, L.G. Hector, Jr., H. Li, S.J. Harris, J. Am. Ceram. Soc., 134 (2012) 15476-15487.

[40] R.W.G. Wyckoff, Crystal Structures, 1 (1963) 85-237.

[41] Y. Idemoto, J.W. Richardson, N. Koura, S. Kohara, C.K. Loong, J. Phys. Chem. Solids, 59 (1998) 363-376.

[42] D.N. Theodorou, U.W. Suter, Macromolecules, 19 (1986) 139-154.

[43] S.L. Teich-McGoldrick, J.A. Greathouse, R.T. Cygan, J. Phys. Chem. C, 116 (2012) 1509915107.

[44] K. Wasanasuk, K. Tashiro, Macromolecules, 45 (2012) 7019-7026.

[45] H. Liu, M. Li, Z.-Y. Lu, Z.-G. Zhang, C.-C. Sun, T. Cui, Macromolecules, 44 (2011) 86508660.

[46] N.B. Shenogina, M. Tsige, S.S. Patnaik, S.M. Mukhopadhyay, Macromolecules, 45 (2012) $5307-5315$.

[47] G. Simmons, H. Wang, Single Crystal Elastic Constants and Calculated Aggregate Properties: A HANDBOOK, 2nd ed., The M.I.T. Press, Cambridge, Massachusetts, and London, 1971.

[48] R. Hill, Proceedings of the Physical Society of London Section A, 65 (1952) 349-355.

[49] B.H. Billings, D.E. Gray, American Institute of Physics handbook, 3rd ed., McGraw-Hill, New York, 1972.

[50] A.M. Andersson, A. Henningson, H. Siegbahn, U. Jansson, K. Edstrom, J. Power Sources, 119 (2003) 522-527.

[51] D. Bar-Tow, E. Peled, L. Burstein, J. Electrochem. Soc., 146 (1999) 824-832. 
[52] R. Dedryvere, H. Martinez, S. Leroy, D. Lemordant, F. Bonhomme, P. Biensan, D. Gonbeau, J. Power Sources, 174 (2007) 462-468.

[53] S. Leroy, H. Martinez, R. Dedryvere, D. Lemordant, D. Gonbeau, Appl. Surf. Sci., 253 (2007) 4895-4905.

[54] A. Xiao, L. Yang, B.L. Lucht, S.-H. Kang, D.P. Abraham, J. Electrochem. Soc., 156 (2009) A318-A327.

[55] A.M. Andersson, K. Edstrom, J. Electrochem. Soc., 148 (2001) A1100-A1109.

[56] K. Edstrom, M. Herstedt, D.P. Abraham, J. Power Sources, 153 (2006) 380-384.

[57] L. Zhao, I. Watanabe, T. Doi, S. Okada, J. Yamaki, J. Power Sources, 161 (2006) 1275-1280.

[58] A. Richter, R. Ries, R. Smith, M. Henkel, B. Wolf, Diamond Relat. Mater., 9 (2000) 170184.

[59] D. Tahk, H.H. Lee, D.-Y. Khang, Macromolecules, 42 (2009) 7079-7083.

[60] I. Zlotnikov, D. Shilo, Y. Dauphin, H. Blumtritt, P. Werner, E. Zolotoyabko, P. Fratzl, Rsc Advances, 3 (2013) 5798-5802.

[61] W. Kiridena, V. Jain, P.K. Kuo, G.Y. Liu, Surface and Interface Analysis, 25 (1997) 383389.

[62] J.-C. Tan, P.J. Saines, E.G. Bithell, A.K. Cheetham, Acs Nano, 6 (2012) 615-621.

[63] S. Humbert, O. Lame, R. Seguela, G. Vigier, Polymer, 52 (2011) 4899-4909.

[64] M.J. Doyle, Polym. Eng. Sci., 40 (2000) 330-335.

[65] J.L. Laugesen, Cem. Concr. Res., 35 (2005) 199-202.

[66] P. Cortona, Phys. Rev. B: Condens. Matter, 46 (1992) 2008-2014.

[67] K. Doll, H. Stoll, Phys. Rev. B: Condens. Matter, 56 (1997) 10121-10127.

[68] Y. Duan, D.C. Sorescu, Phys. Rev. B: Condens. Matter, 79 (2009).

[69] S.-L. Shang, L.G. Hector, Jr., S. Shi, Y. Qi, Y. Wang, Z.-K. Liu, Acta Mater., 60 (2012) $5204-5216$.

[70] N.A. Smirnov, Phys. Rev. B: Condens. Matter, 83 (2011). 
[71] S.F. Pugh, Philos. Mag. A, 45 (1954) 823-843.

[72] J. Maniks, I. Manika, R. Grants, R. Zabels, K. Schwartz, M. Sorokin, R.M. Papaleo, Appl.

Phys. A, 104 (2011) 1121-1128.

[73] M. Sulaiman, A.A. Rahman, N.S. Mohamed, in, ICCM International Conferences on Composite Materials, 2011.

[74] L.G. Schulz, J. Chem. Phys., 17 (1949) 1153-1162. 


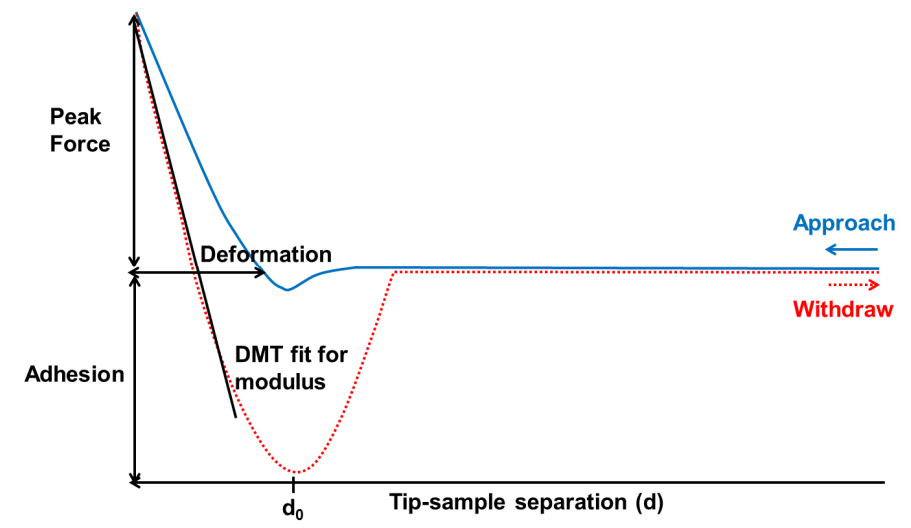

Figure 1
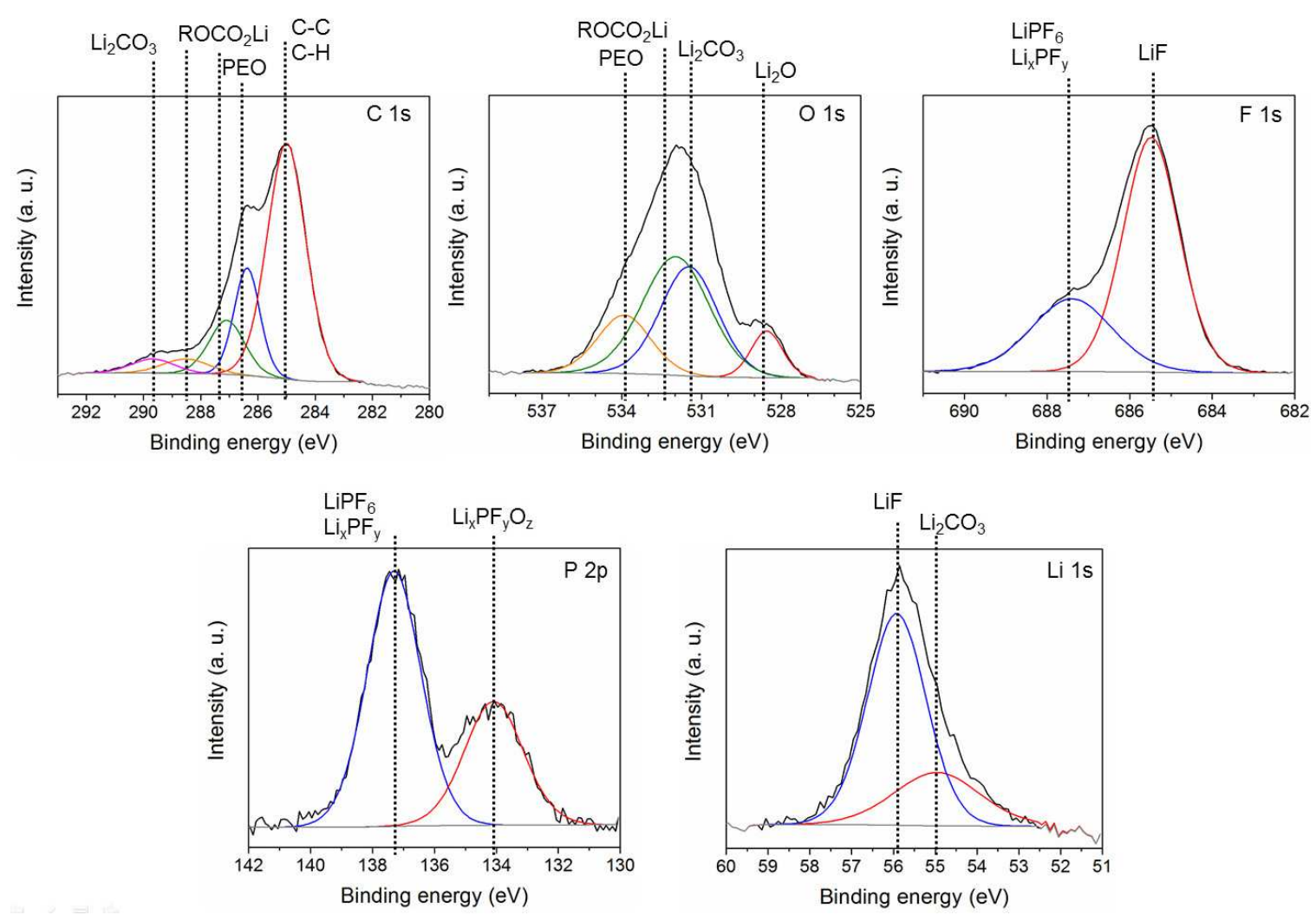

Figure 2 

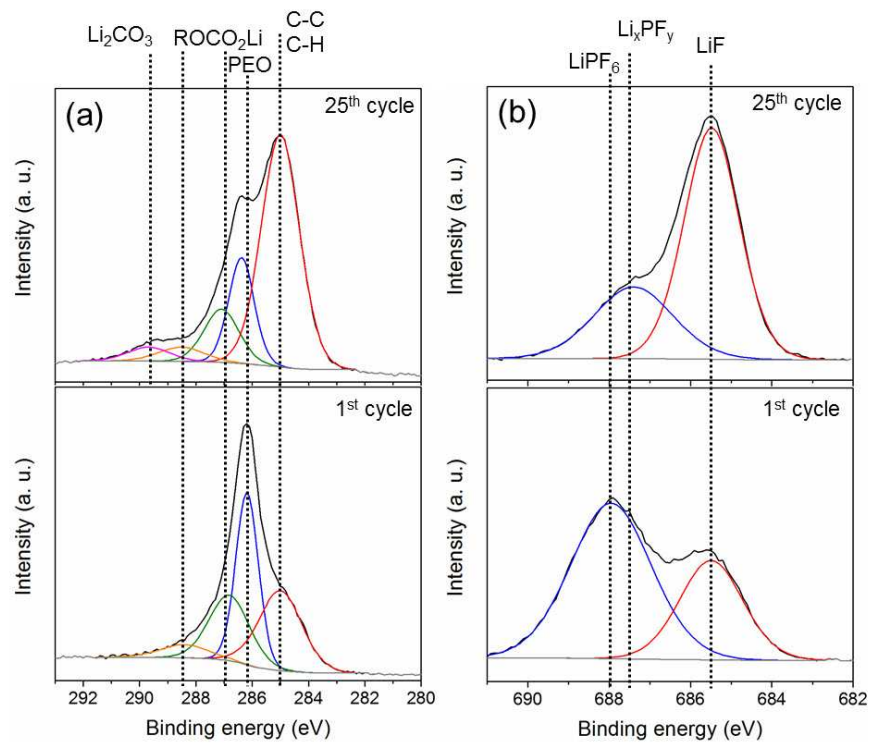

Figure 3 

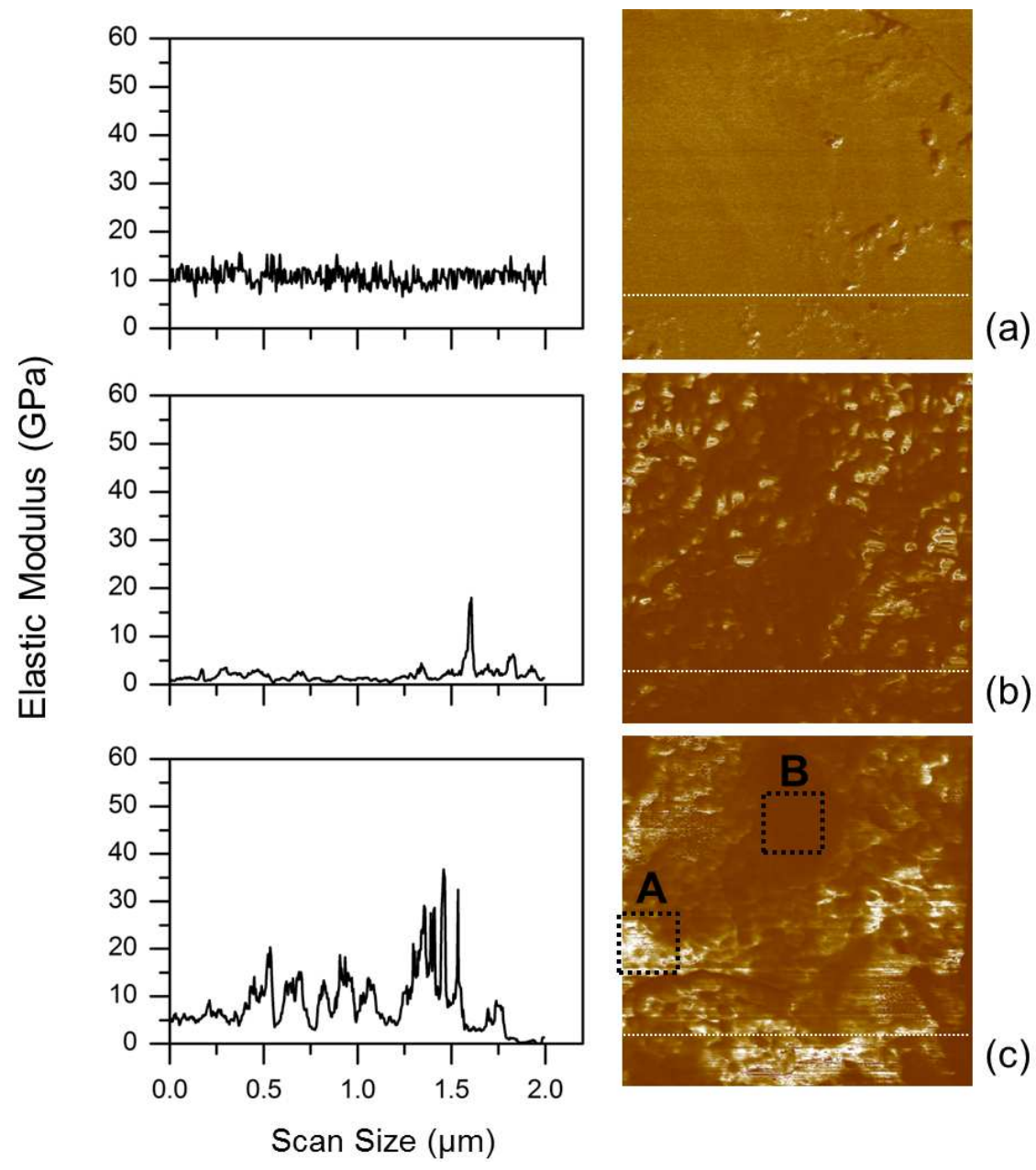

(b)

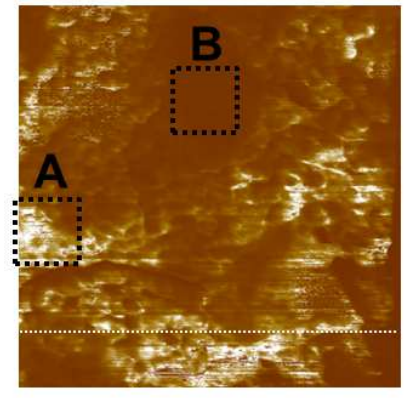

(c)

Figure 4 

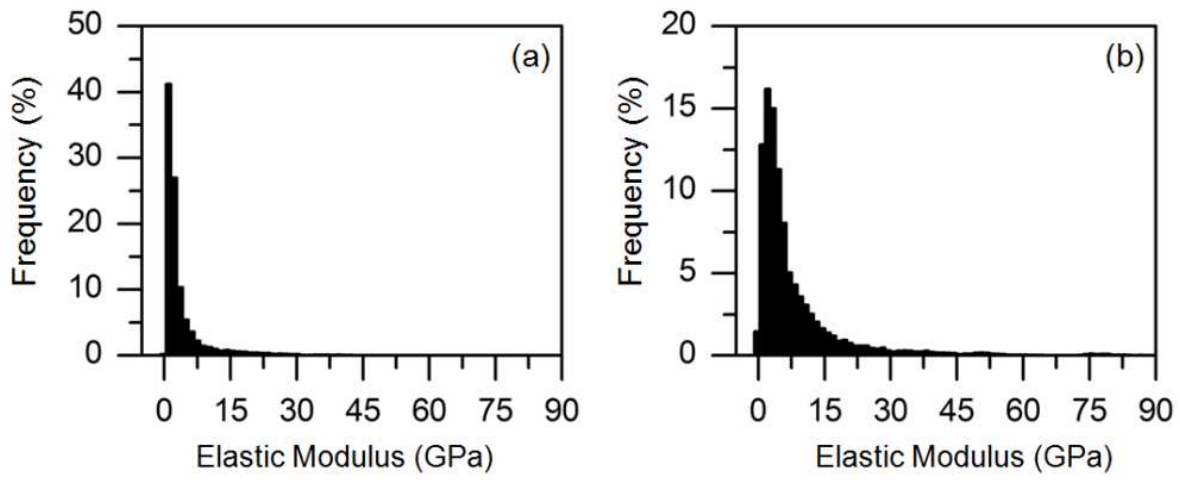

Figure 5 

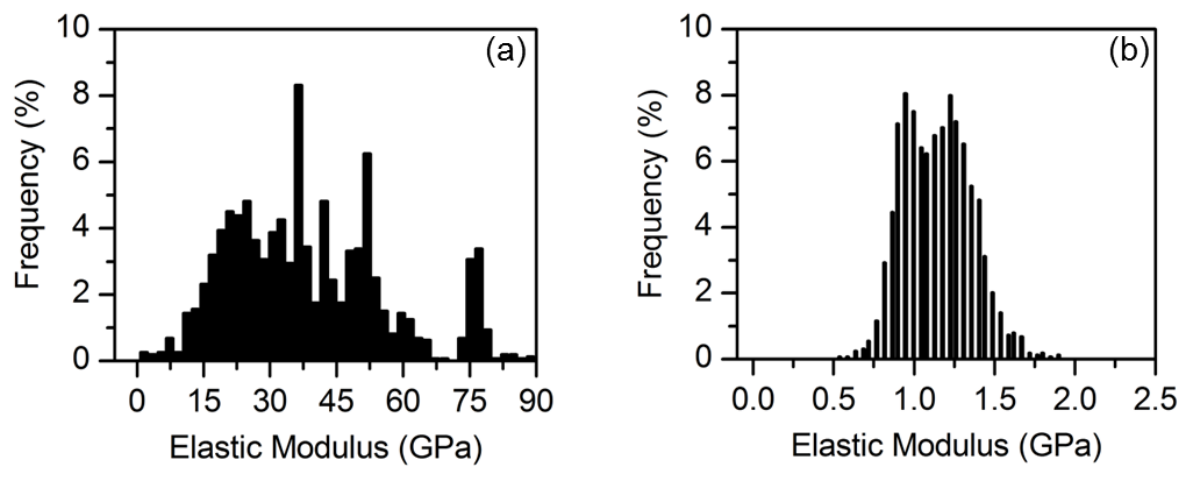

Figure 6 

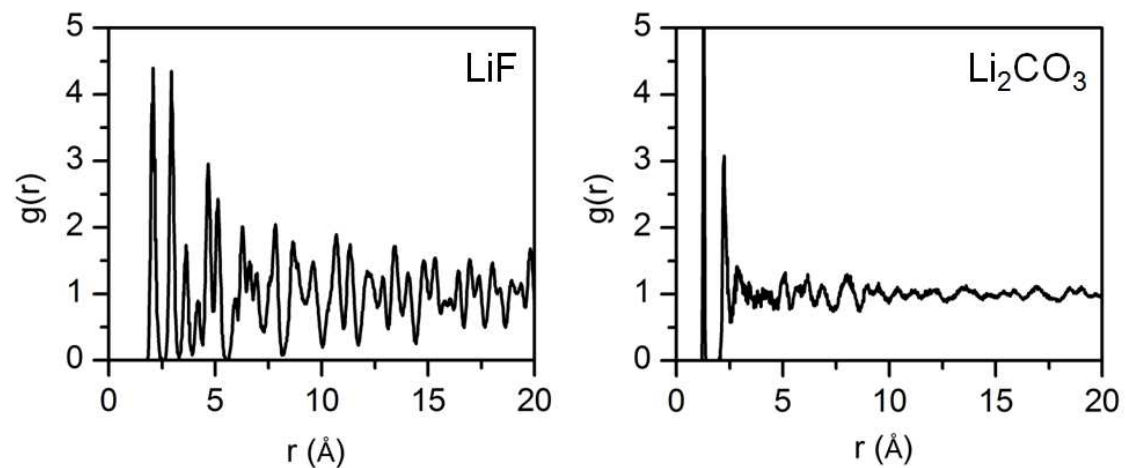

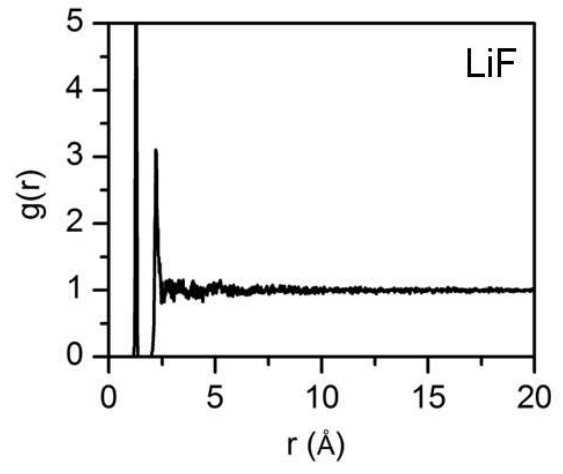

(a)

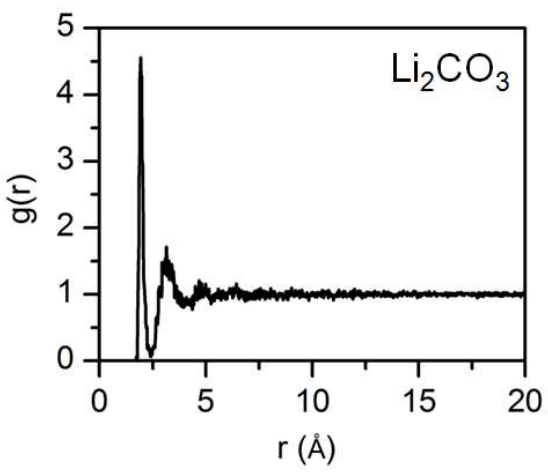

(b)

Figure 7 


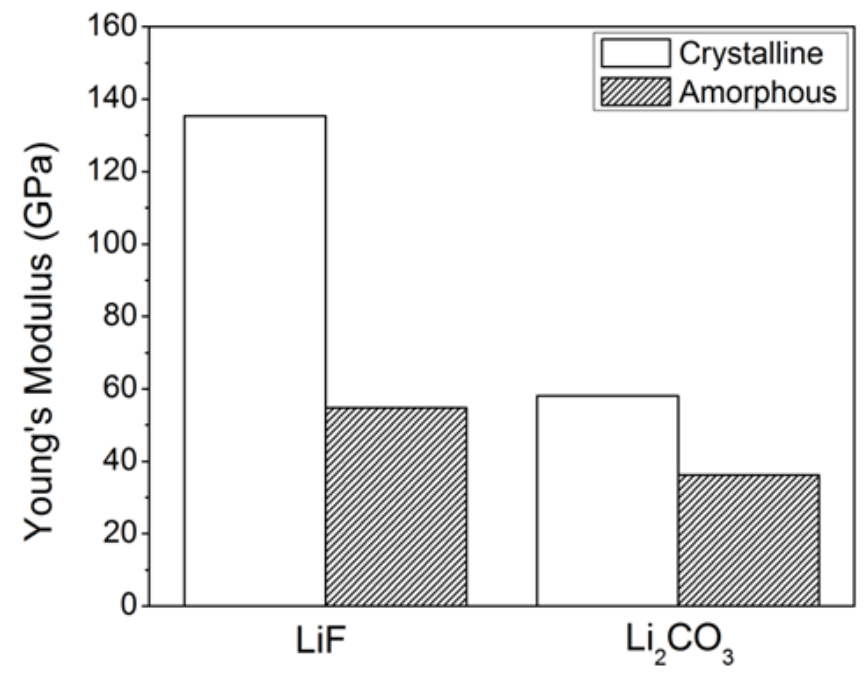

Figure 8 

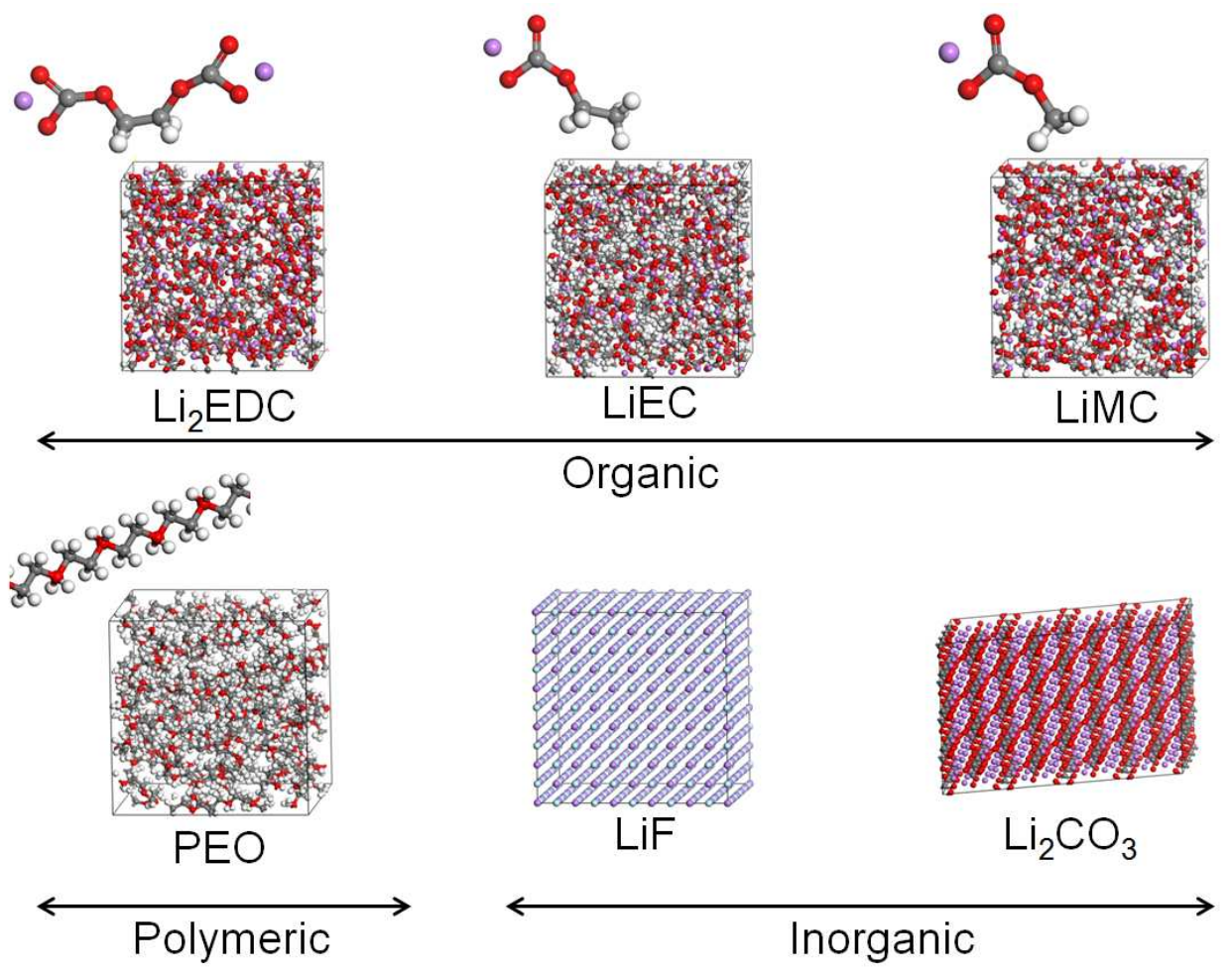

Figure 9 


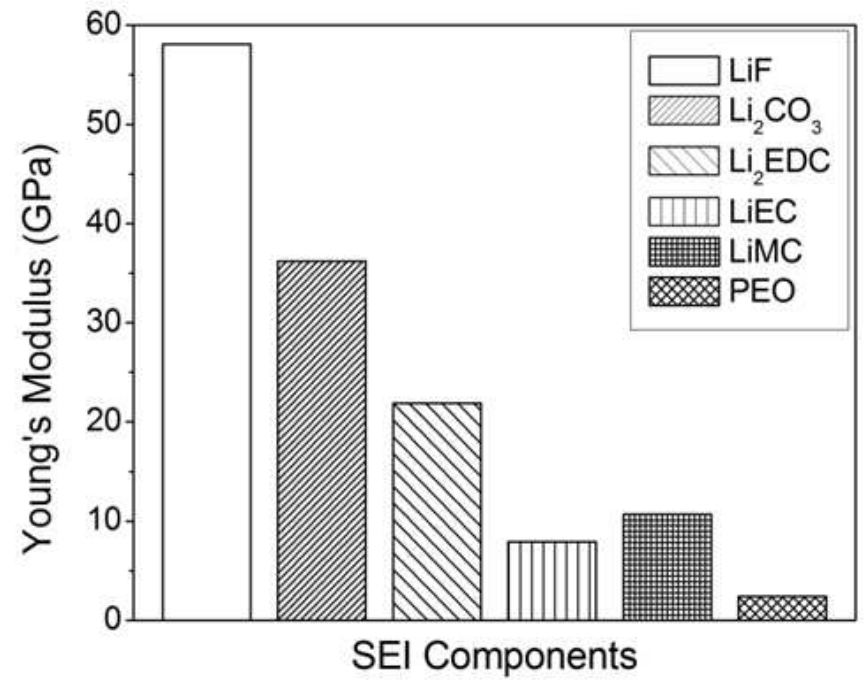

Figure 10 
Table 1

\begin{tabular}{|c|c|c|}
\hline & LiF & $\mathrm{Li}_{2} \mathrm{CO}_{3}$ \\
\hline Experiment & $4.03^{a}$ & $8.36 / 4.97 / 6.19 / 114.79$ \\
\hline Calculation & $3.88 \sim 4.13^{b}$ & $\begin{array}{l}8.41 / 5.03 / 6.30 / 114.80 \\
8.32 / 4.93 / 5.90 / 116.07\end{array}$ \\
\hline This work & 4.18 & $8.94 / 5.11 / 6.19 / 119.53$ \\
\hline
\end{tabular}


Table 2

\begin{tabular}{lcccc}
\hline & \multicolumn{2}{c}{$\mathrm{LiF}$} & \multicolumn{2}{c}{$\mathrm{Li}_{2} \mathrm{CO}_{3}$} \\
\hline & Crystalline & Amorphous & Crystalline & Amorphous \\
\hline $\begin{array}{l}\text { Bulk } \\
\text { modulus (B) }\end{array}$ & 89.4 & 45.5 & 50.5 & 43.1 \\
$\begin{array}{l}\text { Shear } \\
\text { modulus (G) }\end{array}$ & 54.2 & 21.1 & 22.2 & 13.3 \\
B/G & 1.65 & 2.16 & 2.27 & 3.24 \\
\hline
\end{tabular}


Table 3

\begin{tabular}{lcccc}
\hline & Li $_{2}$ EDC & LiEC & LiMC & PEO \\
\hline $\begin{array}{l}\text { Bulk } \\
\text { modulus (B) }\end{array}$ & 18.9 & 5.8 & 8.9 & 2.5 \\
$\begin{array}{l}\text { Shear } \\
\text { modulus (G) }\end{array}$ & 8.4 & 3.1 & 4.1 & 0.9 \\
B/G & 2.25 & 1.87 & 2.17 & 2.77 \\
\hline
\end{tabular}

